\title{
Successful Replantation of an Amputated Thumb : A Case Report
}

\author{
Ricardo Monreal* \\ Centro Medico MEDEX, South America
}

Submission: February 08, 2017; Published: February 15, 2017

*Corresponding author: Ricardo Monreal, Clínicas Maison de Santé, Ave. Chorrillos 171, Chorrillos, Lima, Peru, South America.

\begin{abstract}
The best indication of replantation is first of all, the amputated thumb, among all fingers, since the thumb is functionally the most important digit. Therefore, replantation of the thumb should be attempted even under unfavorable conditions. We report a replantation surgery in a young male patient with an amputation of the thumb between the base of proximal phalanx and the interphalangeal joint.
\end{abstract}

Keywords: Thumb amputation; Replantation; Secondary surgery; Anastomosis

\section{Introduction}

Replantation should be the first indication for treatment of amputated fingers. Among all cases of finger amputations, the thumb is the most appropriate for replantation as this digit plays a key role in hand function. The replantation surgery has progressed since the first successful arm replantation by Malt in 1962 [1], and the first successful thumb replantation by Tamai and Komatsu in 1965 [2].

Replantation has become a routine part of hand surgery field with the advent of refined microscopes, sutures-needles, and specialized surgical training. This case report describes the successful replantation of a thumb amputated between the base of proximal phalanx and the IP joint following an emergency surgery in a young male patient.

\section{Case Report}

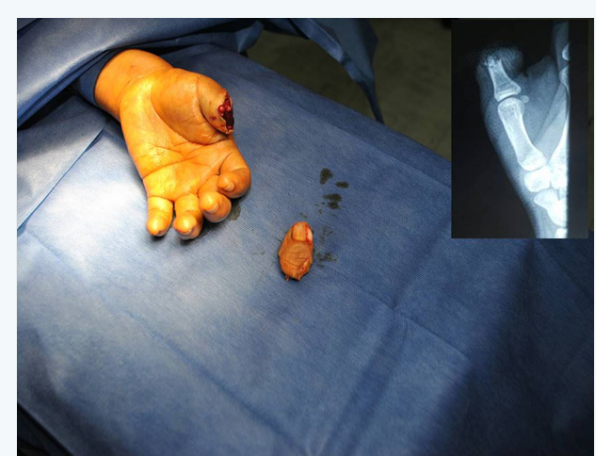

Figure 1: Distal thumb traumatic amputation. Radiograph revealing distal phalanx amputation.
A 29 year old man accidentally cut off his left thumb while he was working. He was sent to our institution 45 minutes after injury. The thumb was completely amputated between the base of proximal phalanx and the IP joint (Zone III according Tamai's classification) [3] (Figure 1). The left arm was anesthetized by brachial plexus block and a pneumatic tourniquet was applied. The thumb was washed with sterile saline and both wound were debrided and bone fusion was done, with one Kirschner wire.

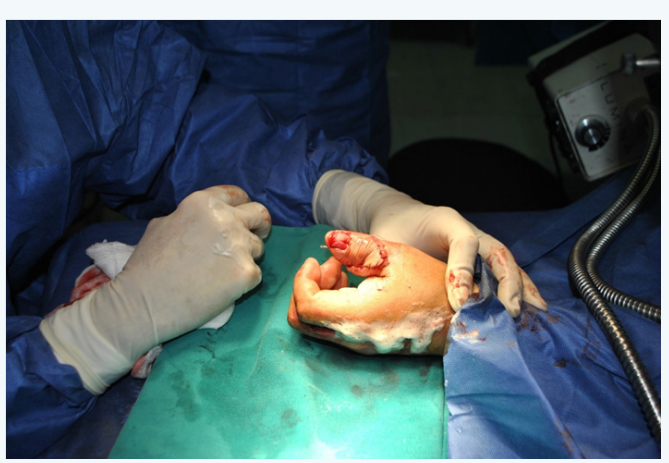

Figure 2: Immediate postoperative appearance of the replanted thumb.

Under a surgical microscope, two volar digital arteries and two dorsal veins were sutures end to end with a traumatic 10-0 monofilament nylon. During the vascular suture, diluted heparin solution was used topically. Immediately after establishment of circulation, the thumb became pink. Pulsation of the digital arteries was noticed and the veins were filled with returning blood (Figure 2). Digital nerves were repaired but the flexor 
tendon and extensor tendon were not sutured due the extensive damage of the cartilage of the interphalangeal joint and an arthrodesis was postponed. The entering operating time was 4 hours but the time spent for vessel suture alone was $1 \frac{1}{2}$ hours.

Slight edema developed from the second postoperative day but after a week the thumb returned to normal. Heparin (200 $\mathrm{mg}$ /day intramuscularly) and low molecular weight dextran (500 cc every day) were given for seven days. Three months after replantation slight atrophy, protective sensation and cartilage damage of the interphalangeal joint were noticed (Figure 3); therefore six months later the arthrodesis of this joint was performed in order to improve stiffness, pain, and contracture.

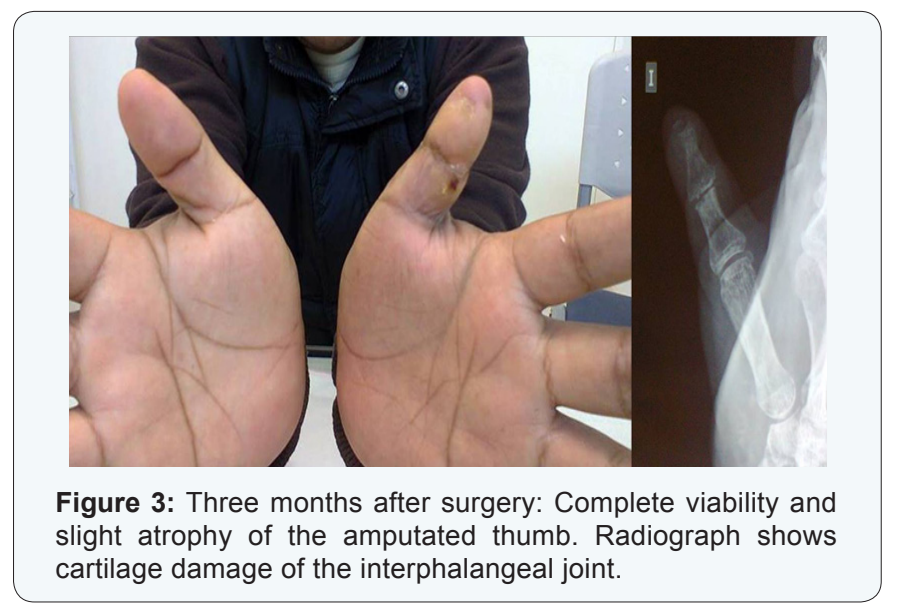

\section{Discussion}

Current literature suggests some indications for reimplantation, such as thumb amputations, multiple fingers amputations, and partial hand amputation, any level of amputations in children, wrist or forearm amputation or single distal finger insertion of the superficial flexor of the finger [4-6]. The thumb is considered the single most important digit and given its critical role in prehension and grasping is responsible for $40 \%$ of hand function [7]. Although amputation of the thumb is not a common injury its consequences can cause psychological changes, permanent functional deficit and inability to work. Thus replantation is indicated in nearly all thumb amputations and with the advent of microsurgical techniques, replantation emerged as an alternative for the treatment of these lesions.

Preservation of thumb length along with adequate functionality and sensory activity is considered as a crucial factor for hand functions. Replantation of the thumb amputatedbetween the base of proximal phalanx and the interphalangeal (IP) joint presents technical difficulties due to narrow arterial diameter and venous problems but advancements in the micro vascular surgery techniques allow high survival rates [8-10]. Secondary surgery has been reported rarely in the thumb replantation literature $[11,12]$. Secondary surgeries are often aimed at combating stiffness, pain, and contracture. In the present case report, secondary surgery was only performed because the patient requested improvement of function and the surgeon's clinical judgment concluded that a secondary procedure would offer a benefit.

\section{Conclusion}

Among all cases of finger amputations, the thumb is the most appropriate indications for replantation. Since this amputation occurs between the base of proximal phalanx and the IP joint of a thumb, functional prognosis is favorable, and patient satisfaction is also generally high. Secondary surgeries are often aimed at combating joint stiffness, pain, and contracture.

\section{Author's disclosure statement}

The authors report no actual or potential conflict of interest in relation to this article.

\section{References}

1. Malt RA, McKhann C (1964) Replantation of severed arms. JAMA 189: 716-722.

2. Komatsu S, Tamai S (1968) Successful replantation of a completely cutoff thumb: Case report. Plast Reconstr Surg 42(4): 374-377.

3. Tamai S (1982) Twenty years' experience of limb replantation-- review of 293 upper extremity replants. J Hand Surg Am 7(6): 549-556.

4. Meyer VE (1985) Hand amputations proximal but close to the wrist joint: prime candidates for reattachment (long-term functional results). J Hand Surg Am 10(6 Pt 2): 989-991.

5. O'Brien BM (1974) Replantation surgery. Clin Plast Surg 1(3): 405-426.

6. O'Brien BM, Miller GD (1973) Digital reattachment and revascularization. J Bone Joint Surg Am 55(4): 714-724.

7. Sharma S, Lin S, Panozzo A, Tepper R, Friedman D (2005) Thumb replantation: a retrospective review of 103 cases. Ann Plast Surg 55(4): 352-356.

8. Dubert T, Houimli S, Valenti P, Dinh A (1997) Very distal finger amputations: replantation or "reposition-flap" repair? J Hand Surg Br 22(3): 353-358.

9. Yamano Y (1985) Replantation of the amputated distal part of the fingers. J Hand Surg Am 10(2): 211-218.

10. Ozcelik, Purisa H, Mersa B, Sezer I, Ertürer E, et al. (2008) Late results of replantations in tip amputations of the thumb. Acta Orthop Traumatol Turc 42(4): 252-257.

11. Rosson GD, Buncke GM, Buncke HJ (2008) Great toe transplant versus thumb replant for isolated thumb amputation: critical analysis of functional outcome. Microsurgery 28(8): 598-605.

12. Earley MJ, Watson JS (1984) Twenty four thumb replantations. J Hand Surg 9(1): $98-102$. 
This work is licensed under Creative Commons Attribution 4.0 License

DOI: 10.19080/OROAJ.2017.04.555650
Your next submission with Juniper Publishers will reach you the below assets

- Quality Editorial service

- Swift Peer Review

- Reprints availability

- E-prints Service

- Manuscript Podcast for convenient understanding

- Global attainment for your research

- Manuscript accessibility in different formats

( Pdf, E-pub, Full Text, Audio)

- Unceasing customer service

Track the below URL for one-step submission https://juniperpublishers.com/online-submission.php 